\title{
From axolotl to zebrafish: a comparative approach to the study of thyroid involvement in ocular development
}

\author{
David L. Williams ${ }^{1}$
}

Received: 10 September 2018 / Revised: 24 October 2018 / Accepted: 14 November 2018 / Published online: 27 November 2018

(c) The Royal College of Ophthalmologists 2018

\begin{abstract}
While discussion of interactions between the thyroid gland and the eye mostly focus on thyroid eye disease, the involvement of the thyroid and its hormones on development of the eye before birth is also an important perspective that should not be forgotten. Experimental models involving amphibians and fish are valuable both because the developing larvae are not constrained within the adult but can be observed and manipulated as they grow autonomously and also because they metamorphose with substantial morphological changes driven by the hypothalamo-pituitary-thyroid axis occurring as they develop from eggs to adults. In this paper we will first discuss changes seen in the axolotl, a naturally occurring neotonous hypothyroid salamander and the Xenopus toad a widely used laboratory amphibian. Secondly we will document ocular changes in flatfish which exhibit remarkable anatomical alterations during their change from a pelagic to benthic lifestyle. Finally we will evaluate ocular changes in developing zebrafish when subjected to thyroid-disrupting chemicals. These experiments show the influence of the thyroid on ocular development when thyroid function is altered which may be of value in determining changes in human hypothyroid infants but are also important to note as these chemicals are widely used in plastics and also as flame retardants used to control wildfires. Run-off into water courses can damage both wildlife and humans consuming contaminated water and thyroid disruption may have significant effects on reproduction and development, although influences on ocular morphology have yet to be investigated.
\end{abstract}

\section{Introduction}

In 1804 Alexander von Humboldt the Prussian polymath, explorer, geographer and naturalist [1] sent two specimens of a very strange animal, preserved in alcohol, from his travels in Mexico to his colleague Georges Cuvier at the Musee d'Anatomie Comparative in Paris [2]. The museum had to wait another 60 years before six live specimens of Ambystoma mexicanum (Fig. 1a), arrived in a huge consignment of animals from Mexico [3]. Humboldt had named it the axolotl, this term derived from its Mexican native name the nahuatl which might be connected with Xolotl the Axtec god of destruction and death [4] or more prosaically simply mean water dog [5]. Auguste Dumeril who received them noted that they were indeed aquatic larvae but within a

David L. Williams

dlw33@cam.ac.uk

1 Department of Veterinary Medicine, University of Cambridge, Madingley Road, Cambridge, UK year they had reproduced, and at a remarkable rate-by 1866 he had amassed 800 progeny [6]. Not only this but some of the animals had metamorphosed into terrestrial adult salamanders [7]. Half a century later on the German biologist JF Gudernatsch was investigating the nutritional requirements of tadpoles by feeding them different body tissues when he noted, in 1911, that feeding thyroid to them caused precocious metamorphosis [8]. Less than a decade later Julian Huxley, working in Oxford, showed that feeding thyroid to axolotls caused their metamorphosis into terrestrial salamander [9]. Unknown to Huxley two researchers in Prague, Edward Babak and Vilem Laufberger were also expending Gubernatch's work to further investigate the influence of the thyroid gland on metamorphosis [10]. Although it was Edward Calvin Kendall who in 1919, working in the laboratories of Parke-Davis and Company, Detroit, Michigan, identified thyroxine as the hormone responsible for the developmental effects of the thyroid gland, the key method for quantifying effects of the hormone for many years was its effect on the axolotl [11].

While the axolotl has been a research animal for 150 years, the zebrafish, (Danio rerio) (Fig. 1b) is a much more 

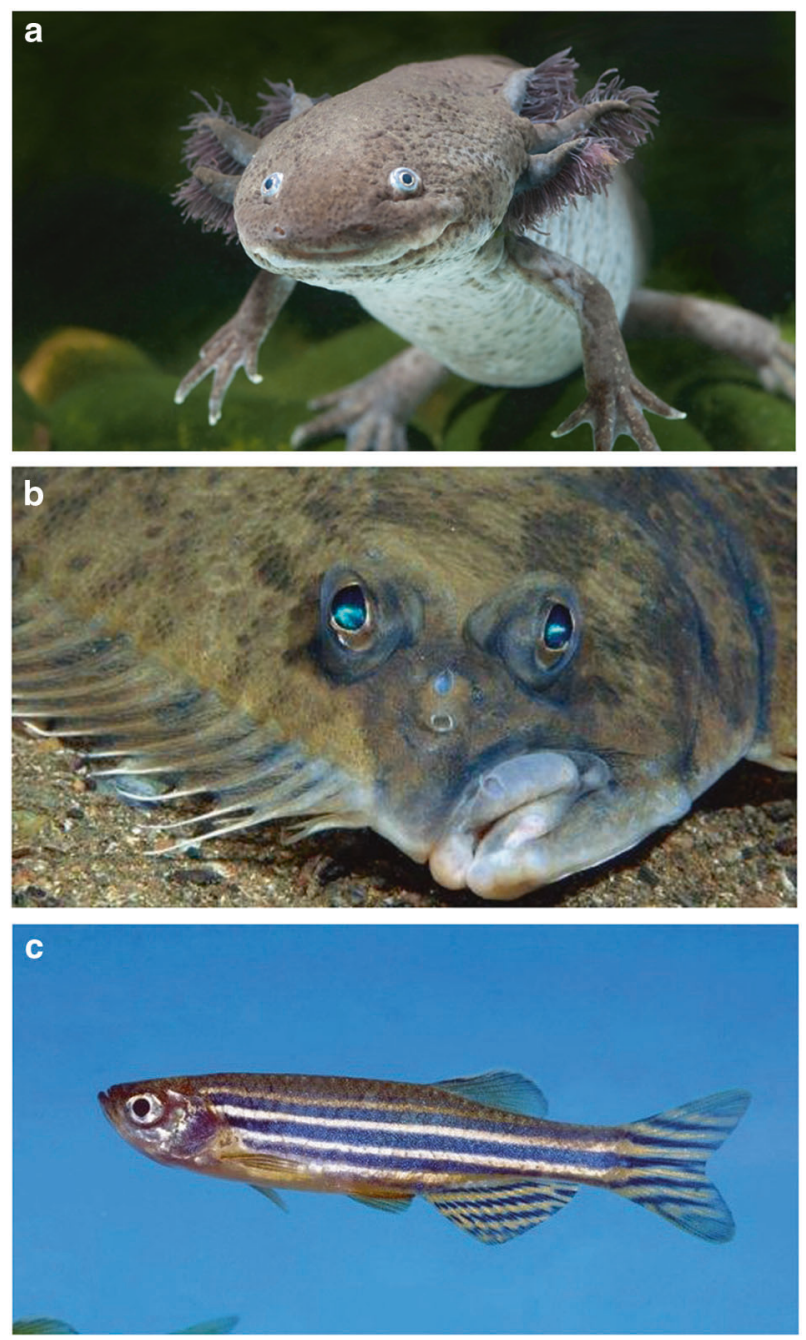

Fig. 1 a Axolorl (Ambystoma mexicanum) b New Zealand Sand Flounder (Rhombosolea plebe). c Zebrafish (Danio rerio)

recent addition to the research laboratory. Kept for many years as a favourite of aquaculture hobbyists, it was George Streisinger who first suggested the zebra Danio as a model system for investigating genetic changes in a vertebrate [12]. The fish is easy to keep, reproduces rapidly with females giving rise to hundreds of progeny with external fertilisation so sperm and eggs can be harvested separately and, importantly from a developmental biology perspective, is readily observed in vivo to allow monitoring of changes without needing to sacrifice fish to evaluate changes as they develop [13]. The eye of the zebrafish shows many features characteristic of any higher vertebrate and its development and morphology have been carefully dissected including a behavioural screen assessing visual function [14]. More remarkable in their thyroid-driven metamorphic development are the flatfish (Fig. 1c) in which, as they develop from larval to adult forms, one eye moves across the body so that both eyes face in the same direction to allow the fish to lie on the sea floor.
One might argue that these organisms are too far removed from mammals to be of use in modelling the involvement of thyroid hormones in human eye development. Yet they have important advantages in the ease of visualisation of ocular changes in the living animal and the opportunities to use various disruptors of thyroid function in evaluating thyroid involvement in ocular morphogenesis.

\section{Investigations in the axolotl and other amphibians}

The axolotl might be described as a thyroid deficient salamander but the exact mechanism of its thyroid defect is still unclear. It has been known for many years that axolotls given thyroid hormones metamorphose into salamanders and more than that axolotls given thyroid stimulating hormone (TSH) metamorphose, so their hypothalmo-pituitarythyroidal system is competent up to the level of the pituitary - the axolotl thyroid gland is certainly sensitive to TSH [15]. But thyrotropic releasing hormone which normally acts to liberate TSH fails to stimulate metamorphosis in axolotls and corticotropin-releasing hormone which should be a potent releaser of TSH fails to stimulate larval axolotls to metamorphosis. The exact mechanism of this failure is still unclear. Molecular genetic analysis of this species is complicated by the fact that the axolotl genome at 32 gigabases is ten times the size of the human genome [16]. Given that congenital hypothyroidism in human patients can be associated with Pax 8 anomalies [17] the reduced Pax family complement in axolotls might be relevant [16] except that it is Pax 3 and 4 which axolotls lack and the human patients with Pax8 mutations have thyroid agenesis, a defect not seen in the axolotl.

With regard to development studies, the axolotl is well known for its exceptional regenerative powers but many have reported that this relates to its limbs alone. More recently researchers have shown that, if only for a limited period, axolotls, as with other urodeles, can regenerate the lens after total lens removal by de-differentiating its posterior cornea into lenticular tissues [18]. What part does the thyroid play in limb or lens regeneration? As we noted above thyroxine stimulates axolotl to metamorphose rather than to regenerate but other molecules which bind to nuclear receptors include retinoic acid which can induce hyper-regeneration and thyroid hormone may interfere with this activity [19].

The African clawed toad Xenopus laevis however is a valuable model for the involvement of thyroid hormones and their receptors in ocular development.

When the Xenopus tadpole metamorphoses its eyes move from being laterally and having non-overlapping visual fields to being dorsolaterally positioned with 
overlapping dorsofrontal visual fields. These changes require not only proliferation and apoptosis of cells around the eye but also changes in the retina and the neuro-retinal projections. Before metamorphosis all axons from the retina cross at the chiasm before most innervate the optic tectum while a few innervate the thalamus. At the time of metamorphosis some ganglion cell axons turn at the chiasm and innervate the ipsilateral thalamus. Thyroid hormone increases neurogenesis, neural differentiation and dendrite arborisation in the tadpole visual system as shown by studies inducing global reduction in thyroid hormone by use of methimazole or local effects by injection of triiodothyronine into specific brain areas [20]. Local effects on thyroid hormones influence which cells move and which do not, as we shall see further below when discussing eye movement in metamorphosing flatfish. The expression of thyroid hormone receptors in Xenopus occurs, somewhat remarkably, before the thyroid itself produces hormones, i.e. at the period of embryogenesis but before metamorphosis when thyroxine is produced and has its effects. We generally think that hormone receptors have their effects when the hormone binds to them. In the premetamorphic amphibian, however, unliganded thyroid receptors, i.e. ones without hormone bound, have a significant role in the developing eye. TR $\beta$ is highly expressed in the retina of the early Xenopus tadpole and induces cell proliferation and photoreceptor differentiation [21]. It appears that the unliganded thyroxine receptor far from merely awaiting hormone to bind before it has an influence, acts as a transcription repressor of genes that normally act as thyroid hormone response elements during metamorphosis. That the same receptors, when bound by hormone act as transcriptional activators. Thus before thyroid hormone production unliganded receptors actively inhibit changes seen at metamorphosis. This is certainly seen in hindlimb development in this frog species and TR $\alpha$ knockout Xenopus shows precocious limb formation, demonstrating that before the hormone is produced, the unbound receptors acts to supress development [21]. Perhaps this is only in amphibians though. Mice lacking thyroxine receptors do not so far suggest a role for unliganded receptors in early development of the mammalian eye. They have been shown to have an effect in the developing mammalian heart through [22], so perhaps the receptor acts as a molecular switch later in eye development. Given that the thyroid hormones promote cell proliferation, perhaps it is important to have quite as much a negative effect when the receptor is not binding the hormone as to have a positive effect when it binds hormone.

Another mechanism of ensuring that thyroid hormones do not have an inappropriate effect where it is not required, is to have a local inhibitor system in the tissues themselves so that the same concentration of hormone can have different effects on cells in different areas. This is seen in the expression of deiodinase enzymes in ocular tissue. This is the mechanism behind asymmetric development of the retina at metamorphosis to allow changes to the visual fields from tadpole to adult. The ciliary marginal zone which is the point of origin of photoreceptors and other cells in the developing retina expresses type II deiodinase dorsally but not ventrally. This abrogates the activity of thyroid hormone locally suppressing neural generation in the ventral ciliary marginal zone. Changes in metamorphosis are not modulated by the production of thyroid hormones far from the eye but also by local enzymatic destruction of hormone where its action is not required.

\section{Investigations in flatfish}

Ocular development in conventional teleost fish such as the zebra Danio seems relatively uneventful compared to the dramatic changes in flatfish of the order Pleuronectiformes [23]. Ranging from $2 \mathrm{~cm}$ to well over $2 \mathrm{~m}$ in length these fish spend the majority of their lives as benthic, that is to say bottom dwelling creatures. This means that they lie on one side or the other with both eyes on the upper side of the body. They start life however as conventional bilaterally symmetrical larval individuals swimming upright in the water column as does any conventional fish. As these larvae metamorphose into their juvenile form they begin to swim more and more horizontally and the bottom eye gradually migrates to join its partner on the upper side of the body. As we might expect, given that this occurs at metamorphosis, all these events are driven by thyroid hormones (Fig. 2) [24]. Both thyroxine and iodothyroxine levels peak at the climax of metamorphosis in the best studied flatfish models, the Japanese flounder, Summer flounder and Atlantic halibut and presumably in other flatfish too. As we saw above though, it is important also to evaluate the distribution of

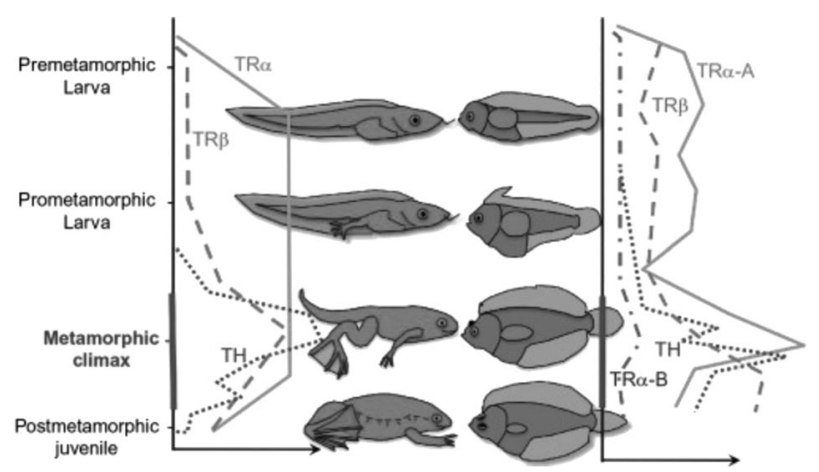

Fig. 2 Changes in thyroid hormone and TH receptors in developing frog and flatfish (From Schreiber AM. Flatfish: an asymmetric perspective on metamorphosis. Current topics in developmental biology 2013;103:167-194. with permission) 
thyroid hormone receptors and of deiodinating enzymes in ocular and periocular tissues. Expression of deiodinases are upregulated in flatfish metamorphosis, but there is not necessarily agreement between different researchers with regard to the exact changes in deiodinases 1,2 and 3 . Some find a rise in deiodinase 2 , which deiodinates the outer ring of the prohormone thyroxine activating it, together with a sharp drop in deiodinase 3 which deiodinates the inner ring of thyroxine deactivating it [25]. There is a rise in $\operatorname{TR} \alpha$ and $\operatorname{TR} \beta$ expression too at metamorphosis although the different expressions of these two isoforms may explain the apparently opposing effects of thyroid hormone on different tissues.

Endocrine signals are critical in mediating the skull remodelling that occurs during metamorphosis but these are more than merely thyroid hormones-insulin-like growth factor receptors are expressed in fibroblasts around the eye for instance, although elevated concentration of thyroid hormones are key in inducing migration of the lower eye and if endogenous production of thyroid hormones is prevented the fish retain a symmetrical skull without any eye migration [26]. Having said all that tilted swimming behaviours and feeding as if benthic not pelagic appear to occur before eye migration starts and treatment of symmetric larvae with thyroid hormones induces tilted swimming and settling behaviour on the tank floor before any eye migration and skull remodelling occurs, so it may be that lateralised behaviour precedes physical changes. These behaviour changes are related not so much to changes in eye position but in inner ear morphology, semi-circular canal orientation and vestibular function which might be more sensitive to low levels of thyroid hormones. While the eyes are the most obvious structures changing in metamorphosing flatfish larvae we must not forget that the whole animal is changing during this critical developmental stage [27].

\section{Investigations in zebrafish}

As with all vertebrates the embryonic thyroid tissue originates in the definitive endoderm and inactivation of genes key in endoderm formation such as bon, cas and oep lead to impaired thyroid formation [28]. In contrast to the situation in humans though TSHR activation is essential to thyroid differentiation [29]. Low dose inhibition of thyroid function in zebrafish can be produced using methimazole. This supresses thyroid peroxidase the key enzyme in tyrosine iodination and the binding of iodinated tyrosine to thyroglobulin. Microphthalmia thus results associated with a reduction in the thickness of both the inner plexiform layer and the ganglion cell layer [30]. These changes are unlikely to be caused by a generalised developmental delay as other growth parameters were unchanged and the dose of methimazole used was sub-toxic. The ocular changes noted with thyroid dysfunction in these experimental zebrafish are not only important as a model for thyroid involvement in mammalian ocular development. Environmental contamination by endocrine disrupting compounds such as bisphenol $\mathrm{S}$ (4.4'sulphonyldiphenol) is a major concern. This product is widely employed in epoxy resins and polycarbonate drinks containers but also as a flame retardant dropped in sizeable quantities to stop forest fires and can have significant effects on thyroid function on both wildlife in the areas in which it is used [31] and in humans through ingestion from run-off when water courses are contaminated [32]. Bisphenol induced irregular photoreceptor development, reduced the inner plexiform layer and ganglion cell layer in the same manner as other thyroid-disrupting compounds and reduced visual functions such as tracking behaviour and the optomotor reflex [33]. Exposure to nanomolar concentrations of environmental contaminants at levels documented in field surveys lead to morphological and cellular changes in the eyes of zebrafish larvae and alterations in swimming activity and light-dark preferences in a laboratory setting [34]. We know a good deal about the endocrine disrupting effects of these pollutants [35] but the ocular changes related to thyroid dysfunction through such contamination have yet to be fully investigated.

\section{Compliance with ethical standards}

Conflict of interest The author declares that he has no conflict of interest.

\section{References}

1. Wulf A The invention of nature: Alexander von Humboldt's New World. Knopf; 2015.

2. Reiß C, Olsson L, Hoßfeld UW. The history of the oldest self-sustaining laboratory animal: 150 years of axolotl research. J Exp Zool Part B: Mol Dev Evol. 2015;324:393-404.

3. Dunbar GS. "The compass follows the flag": the French scientific mission to Mexico, 1864-1867. Ann Assoc Am Geogr. 1988;78: 229-40.

4. Neumann FJ. The dragon and the dog: two symbols of time in Nahuatl religion. Numen. 1975;22:1.

5. Smith HM. The Mexican axolotl: some misconceptions and problems. Bioscience. 1969;19:593-615.

6. Dumeril A. Observations sur la reproductions dans la menagerie des reptiles du Museum d'Histoire Naturelle, des axolotls, batraciens urodeles a branchies exterieures du Mexique, sur leur developement et sur leur metamorphoses. Nouv Arch Mus Hist Nat. 1866;2:265-92.

7. Duméril MA. Experiments on the axolotl. Ann Mag Nat Hist. 1867;20:446-9.

8. Gudernatsch JF. Feeding experiments on tadpoles. Arch für Entwickl der Org. 1912;35:457-83.

9. Huxley JS. Metamorphosis of axolotl caused by thyroid-feeding. Nature. 1920;104:435. 
10. Babak E. Einige gedanken uber die Beziehung der metamorphose bei den Amphibien zur inneren secretion. Zent fur Physiol. 1913;27:536-41.

11. Mørch JR. Standardization of thyroid preparations. J Physiol. 1929;67:221-41.

12. Varga M. The Doctor of Delayed Publications: The Remarkable Life of George Streisinger (1927-1984). Zebrafish. 2018;15: 314-9.

13. Grunwald DJ, Eisen JS. Headwaters of the zebrafish-emergence of a new model vertebrate. Nat Rev Genet. 2002;3:717.

14. Fadool JM, Brockerhoff SE, Hyatt GA, Dowling JE. Mutations affecting eye morphology in the developing zebrafish (Danio rerio). Dev Genet. 1997;20:288-95.

15. De Groef B, Grommen SV, Darras VM. Forever young: endocrinology of paedomorphosis in the Mexican axolotl (Ambystoma mexicanum). Gen Comp Endocrinol. 2018;266: 194-201.

16. Nowoshilow S, Schloissnig S, Fei JF, Dahl A, Pang AW, Pippel $\mathrm{M}$, et al. The axolotl genome and the evolution of key tissue formation regulators. Nature. 2018;554:50-7.

17. Macchia PE, Lapi P, Krude H, Pirro MT, Missero C, Chiovato L, et al. PAX8 mutations associated with congenital hypothyroidism caused by thyroid dysgenesis. Nat Genet. 1998;19:83.

18. RioTsonis KD, Tsonis PA. Eye regeneration at the molecular age. Dev Dyn. 2003;226:211-24.

19. Crawford K, Vincenti DM. Retinoic acid and thyroid hormone may function through similar and competitive pathways in regenerating axolotls. J Exp Zool. 1998;282:724-38.

20. Thompson CK, Cline HT. Thyroid hormone acts locally to increase neurogenesis, neuronal differentiation, and dendritic arbor elaboration in the tadpole visual system. J Neurosci. 2016; 36:10356-75

21. Havis E, Le Mevel S, Dubois GM, Shi DL, Scanlan TS, Demeneix BA, et al. Unliganded thyroid hormone receptor is essential for Xenopus laevis eye development. EMBO J. 2006;25:4943-51.

22. Mai W, Janier MF, Allioli N, Quignodon L, Chuzel T, Flamant F, et al. Thyroid hormone receptor $\alpha$ is a molecular switch of cardiac function between fetal and postnatal life. Proc Natl Acad Sci. 2004;101:10332-7.

23. Schreiber AM. Flatfish: an asymmetric perspective on metamorphosis. Curr Top Dev Biol. 2013;103:167-94.
24. Power DM, Einarsdóttir IE, Pittman K, Sweeney GE, Hildahl J, Campinho MA, et al. The molecular and endocrine basis of flatfish metamorphosis. Rev Fish Sci. 2008;16(sup1):95-111.

25. Isorna E, Obregon MJ, Calvo RM, Vázquez R, Pendón C, Falcón $\mathrm{J}$, et al. Iodothyronine deiodinases and thyroid hormone receptors regulation during flatfish (Solea senegalensis) metamorphosis. J Exp Zool Part B: Mol Dev Evol. 2009;312:231-46.

26. Okada N, Takagi Y, Tanaka M, Tagawa M. Fine structure of soft and hard tissues involved in eye migration in metamorphosing Japanese flounder (Paralichthys olivaceus). Anat Rec Part A. 2003;273:663-8

27. Schreiber AM. Asymmetric craniofacial remodelling and lateralized behavior in larval flatfish. J Exp Biol. 2006;209:610-21.

28. Alt B, Reibe S, Feitosa NM, Elsalini OA, Wendl T, Rohr KB. Analysis of origin and growth of the thyroid gland in zebrafish. Dev Dyn. 2006;235:1872-83.

29. Opitz R, Maquet E, Zoenen M, Dadhich R, Costagliola S. TSH receptor function is required for normal thyroid differentiation in zebrafish. Mol Endocrinol. 2011;25:1579-99.

30. Reider M, Connaughton VP. Effects of low-dose embryonic thyroid disruption and rearing temperature on the development of the eye and retina in zebrafish. Birth Defects Res Part B: Dev Reprod Toxicol. 2014;101:347-54.

31. Flint S, Markle T, Thompson S, Wallace E. Bisphenol A exposure, effects, and policy: a wildlife perspective. J Environ Manag. 2012;104:19-34.

32. Richardson SD, Kimura SY. Emerging environmental contaminants: challenges facing our next generation and potential engineering solutions. Environ Technol Innov. 2017;8:40-56.

33. Liu W, Zhang X, Wei P, Tian H, Wang W, Ru S. Long-term exposure to bisphenol $\mathrm{S}$ damages the visual system and reduces the tracking capability of male zebrafish (Danio rerio). J Appl Toxicol. 2018;38:248-58.

34. Baumann L, Ros A, Rehberger K, Neuhauss SC, Segner H. Thyroid disruption in zebrafish (Danio rerio) larvae: Different molecular response patterns lead to impaired eye development and visual functions. Aquat Toxicol. 2016;172:44-55.

35. Haq I, Raj A. Endocrine-Disrupting Pollutants in Industrial Wastewater and Their Degradation and Detoxification Approaches. Emerging and Eco-Friendly Approaches for Waste Management. Singapore: Springer; 2019. pp. 121-42. 